\title{
Thrombomodulin expression in colorectal carcinoma is protective and correlates with survival
}

\author{
AM Hanly', M Redmond', DC Winter', S Brophy', JM Deasy', DJ Bouchier-Hayes' and EW Kay*,2 \\ 'Department of Surgery, Royal College of Surgeons in Ireland, Beaumont Hospital, Dublin, Ireland; '2 Department of Histopathology, Royal College of \\ Surgeons in Ireland, Beaumont Hospital, Dublin, Ireland
}

Thrombomodulin (TM) is an endothelial receptor that exhibits anticoagulant, antifibrinolytic and anti-inflammatory activity by inhibiting thrombin and cellular adhesion. In this study, the expression and significance of TM was examined in primary colorectal cancer and its prognostic implications explored. TM immunostaining was performed on formalin-fixed, paraffin-embedded tissue sections, from primary lesions of 200 patients with colorectal carcinoma. Institutional Ethical approval was granted and clinical data retrieved from patients' records. All normal colonic tissue expressed TM on endothelial cells. TM tumour cell expression was demonstrated in 53 (26.5\%) cases and I 47 (73.5\%) showed no neoplastic cell staining. On univariate and multivariate analysis TM expression on tumour cells correlated significantly with tumour stage, differentiation, Jass score and 5 year survival. TM expression decreases as overall stage and tumour size increase $(P=0.03)$. In all, 91\% TM positive tumours were well differentiated and $85 \%$ of TM negative tumours were poorly differentiated $(P<0.01)$. Five year survival rates of patients with positive and negative TM expression were $7 \mathrm{I}$ and $41 \%$, respectively. Survival rate was poorer in those patients who were TM negative compared with those who were positive $(P<0.0 \mathrm{I})$. A total of I 0 I $(50.5 \%)$ of the cases were node negative. In this group, 5 year survival rates of patients with positive and negative TM expression were 87.5 and $37.8 \%$, respectively, demonstrating a poorer survival rate for those who are node negative and TM negative at the time of surgery $(P<0.001)$. This study demonstrates that loss of TM is a key indicator in tumour biology and prognosis.

British Journal of Cancer (2006) 94, I320- 1325. doi:I0.1038/sj.bjc.6603098 www.bjcancer.com

Published online 18 April 2006

(C) 2006 Cancer Research UK

Keywords: thrombomodulin; colorectal

Thrombomodulin (TM) is a membrane-bound glycoprotein initially identified on vascular endothelium and later on leucocytes, mesothelium, keratinocytes and astrocytes. Expression is affected by a range of pathophysiological stimuli (Maruyama et al, 1985; Dittman et al, 1989; Ohji et al, 1995; Calnek and Grinnell, 1998; Ishii et al, 2003; Shi et al, 2003) and the effect of a specific stimulus varies with the cell type involved (Grey et al, 1998).

TM plays a role in three major processes in vivo: coagulation, inflammation and cell adhesion. It was discovered by its anticoagulant activity, to be an essential co-factor for thrombinmediated activation of Protein C (Esmon and Owen, 1981, 2004) and thrombin-activated fibrinolysis inhibitor (TAFI) (de Munk et al, 1991), both of which demonstrate fibrinolytic activity. Through these mechanisms, the function of TM as a natural anticoagulant has been well documented.

The anti-inflammatory role of TM has been clearly demonstrated in vivo. It reduces restenosis (Waugh et al, 1999), modifies the inflammatory response (Weiler et al, 2001), prevents leucocyte infiltration (Ikeguchi et al, 2002), and these effects are mediated by a range of mechanisms (Weiler et al, 2001; Conway et al, 2002).

*Correspondence: Professor EW Kay; E-mail: elainekay@beaumont.ie Received 31 October 2005; revised 27 February 2006; accepted 15 March 2006; published online 18 April 2006
The role of TM in malignancy is, in contrast relatively unknown. TM expression has been immunohistochemically demonstrated in a wide variety of human tumours, (Tezuka et al, 1995; Hamatake et al, 1996; Kim et al, 1997; Ordonez, 1997; Tabata et al, 1997; Wilhelm et al, 1998; Zhang et al, 1998; Ogawa et al, 2000), which mostly reveal a correlation between reduced TM expression and shorter survival or increased metastases (Hamatake et al, 1996; Kim et al, 1997; Tabata et al, 1997; Ogawa et al, 2000).

The exact mechanism(s) by which TM acts within a tumour has not been clearly outlined. Anticoagulation, adhesion, differentiation and proliferation have all been suggested. What is known is that malignancy has a profound impact on the haemostatic system, with increasing recognition of the role in tumour biology of coagulation factors, anticoagulants, activators and inhibitors of fibrinolysis (Iqbal, 2000). TM may, therefore, influence tumour growth and metastasis via its role as a natural anticoagulant. TM expression is concentrated in regions of cell to cell contact (Jackson et al, 1995; Tezuka et al, 1995). It has also been demonstrated to colocalize with actin filaments (Huang et al, 2003) suggesting an involvement in intercellular communication or (cell-cell) adhesion. Mirroring other cell-adhesion molecules, TM expression tends to be lower in metastatic lesions than in matched primary specimens (Tezuka et al, 1995; Hamatake et al, 1996; Tabata et al, 1997; Ogawa et al, 2000).

TM is expressed during embryonic development and is associated with cell differentiation (Imada et al, 1990). In oral 
squamous epithelium, TM expression reduces in parallel with the transition from normal mucosa to dysplasia and overt carcinoma (Tabata et al, 1995). In tumours, therefore, decreased TM may induce loss of differentiation and enhance metastatic behaviour. In vitro work has demonstrated that TM reduces tumour cell proliferation and invasion (Matsushita et al, 1998; Zhang et al, 1998; Hosaka et al, 2000; Huang et al, 2003) and TM expressing cells produce smaller tumours in vivo (Zhang et al, 1998; Huang et al, 2003). There are, therefore, many possible mechanisms by which increased TM expression could decrease the likelihood of metastasis.

$\mathrm{TM}$ is not as prevalent in adenocarcinomas as in squamous cell carcinomas. In one study, $<20 \%$ of adenocarcinomas of the pancreas, breast and lung were found to express TM, with no expression seen in prostatic or colonic adenocarcinoma. However, only a small number of specimens were examined (Ordonez, 1997). In a small study of 21 patients with colonic adenocarcinoma, expression on the vasculature increased as tumours progressed along the dysplasia-carcinoma sequence (Takebayashi et al, 1995). Expression of TM in colonic adenocarcinoma has not previously been examined in a large cohort. The aim of this study was to examine TM expression in tissue extracts of patients with primary colorectal cancer and determine if this correlates with tumour stage and prognosis.

\section{MATERIALS AND METHODS}

Specimens from 200 consecutive patients who underwent surgery for primary adenocarcinoma of the colon between 1994 and 1999 were included in this study. The median (range) age of patients was $69(34-90)$ years (male 66.5\%, female $33.5 \%$ ). Patients with radiological evidence of metastasis, or who had preoperative chemo or radiotherapy, were excluded. Ethics approval was granted and relevant information was collected from clinical records, primary care physicians and, where necessary, patient contact. Location of tumours, overall stage and tumour stage classified by the TNM classification are outlined in Tables 1, 2 and 3, respectively. Evaluation of malignancy was based on original haematoxylin and eosin stained sections at the time of diagnosis. TM expression in the primary tumours was examined immunohistochemically. Formalin-fixed paraffin-embedded colorectal tumours were retrieved from the archives. Sections were

Table I Distribution of primary tumours within the colon

\begin{tabular}{lc}
\hline Site of tumour & Number of tumours \\
\hline Recto-sigmoid & 82 \\
Left colon & 46 \\
Transverse colon & 8 \\
Right colon & 31 \\
Caecum & 33 \\
\hline
\end{tabular}

Table 2 Comparison of overall colonic tumour stage as defined by the American joint committee on colorectal cancer (AJCC), with positive and negative TM expression groups

\begin{tabular}{lcccc}
\hline Stage & $\begin{array}{c}\text { No. } \\
\text { patients }\end{array}$ & $\begin{array}{c}\text { TM-positive } \\
(\%)(\boldsymbol{n}=\mathbf{5 6})\end{array}$ & $\begin{array}{c}\text { TM-negative } \\
(\%)(\boldsymbol{n}=\mathbf{I 4 4})\end{array}$ & P-Value \\
\hline I & 17 & $9(52.9 \%)$ & $8(47.1 \%)$ & $* P=0.08$ \\
II & 84 & $23(27.4 \%)$ & $61(72.6 \%)$ & \\
III & 99 & $24(24.2 \%)$ & $75(75.8 \%)$ &
\end{tabular}

*Overall analysis of variance. *Comparison of stage I vs $\| \rightarrow P=0.06$, I vs $\| I \rightarrow$ $\mathrm{P}=0.025, \|$ vs $\| \mathrm{I} \rightarrow \mathrm{P}=0.63$. cut at $4 \mu \mathrm{m}$, deparaffinised and rehydrated in descending grades of alcohol $(100-70 \%)$. Following heat-mediated antigen retrieval, slides were run on an automated immuno-stainer (Nexes from Ventana, AZ, USA). Primary antibody was a mouse monoclonal antibody raised against the EGF domains 4-6 of TM (Dako

Table 3 Correlation of tumour stage (AJCC) with TM positive and negative groups

\begin{tabular}{|c|c|c|c|c|}
\hline $\begin{array}{l}\text { Tumour } \\
\text { grade }\end{array}$ & $\begin{array}{l}\text { No. of } \\
\text { patients }\end{array}$ & $\begin{array}{c}\text { TM-positive (\%) } \\
(n=56)\end{array}$ & $\begin{array}{l}\text { TM-negative } \\
(\%)(n=144)\end{array}$ & P-Value \\
\hline $\mathrm{TI}$ & 2 & I (50\%) & I (50\%) & $* P=0.03$ \\
\hline $\mathrm{T} 2$ & 28 & $14(50 \%)$ & $14(50 \%)$ & \\
\hline T3 & 147 & 35 (23.8\%) & I I 2 (76.2\%) & \\
\hline $\mathrm{T} 4$ & 23 & $6(26.1 \%)$ & 17 (73.9\%) & \\
\hline
\end{tabular}

*Overall analysis of variance.

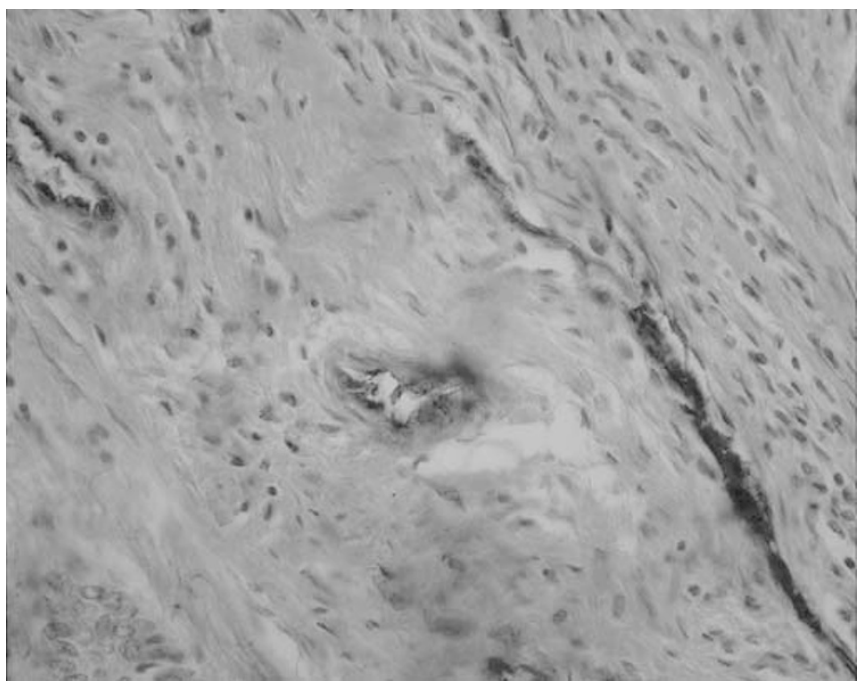

Figure I This slide demonstrates a TM negative tumour with internal positive control staining of the vessel endothelium. The slide is magnified to demonstrate this clearly.

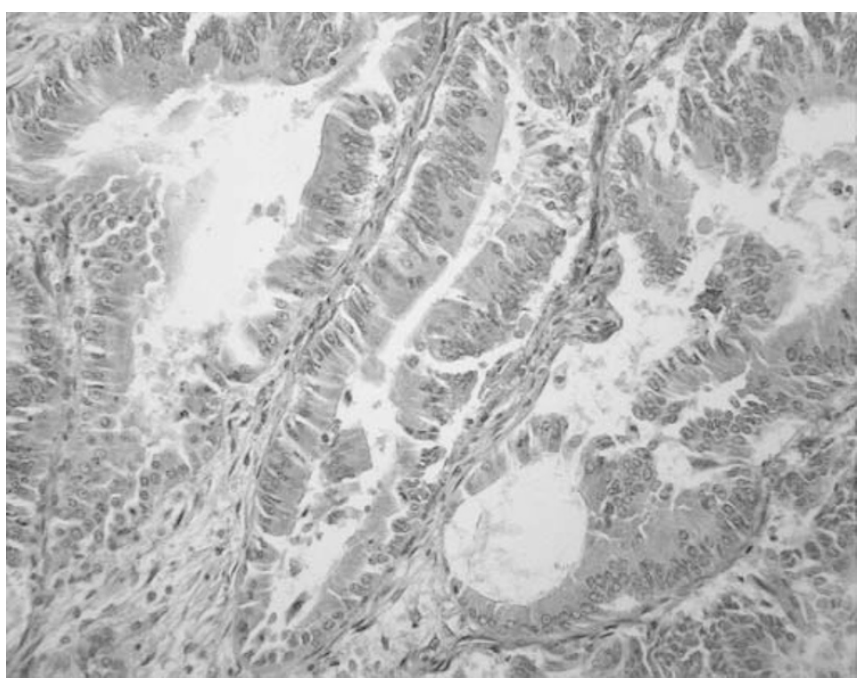

Figure 2 This slide demonstrates a section of colorectal tumour with +1 TM staining, internal positive control is also evident in this image. 


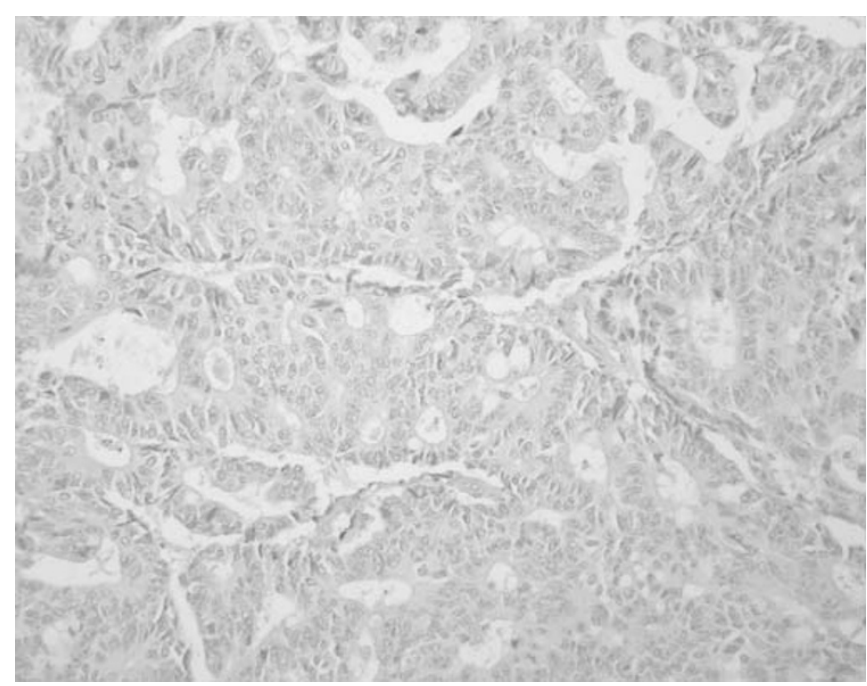

Figure 3 Isotype-matched primary monoclonal antibody negative control.

Glostrup, Denmark; 1:50 dilution). The immunostaining was developed using diaminobenzidine as a chromagen. Vascular endothelium acted as a positive internal control (Figures 1 and 2), the primary antibody was omitted for negative controls and this was confirmed using an isotype-matched primary monoclonal antibody (DAKO Cytomation M0792 at 1:2000 dilution) (Figure 3). Results were quantitatively evaluated by two blinded pathologists. Slides were graded according to intensity of staining on tumour cells and were classified as 0 , completely negative; +1 , under $10 \%$ of neoplastic cells stained; $+210-50 \%$ of neoplastic cells stained and +3 over $50 \%$ of neoplastic cells stained. No slides demonstrated +3 staining and no statistical difference was noted between +1 and +2 staining when compared with tumour grade, stage and overall survival. Therefore, analysis was performed using two groups, TM positive and TM negative.

Statistical analysis was performed using Stats Direct (version 2.3.8. Cheshire, UK). Expression rates of TM were analysed using the Mann-Whitney $U$-test. Clinical outcome data was evaluated using the $\chi^{2}$ and Kaplan-Meier method. A probability of $P<0.05$ was considered statistically significant.

\section{RESULTS}

Endothelial cell TM expression was identical in normal and neoplastic colonic tissue, which acted as a positive internal control. Interestingly, however, epithelial TM expression revealed a marked difference with 7.8 and $26.5 \%$ TM positivity in normal and neoplastic colonic tissue, respectively. TM tumour cell expression was demonstrated on $53(26.5 \%)$ tumours and 147 (73.5\%) showed no neoplastic cell staining. Tables 2 and 3 compare TNM staging with positive and negative TM expression groups. This significantly demonstrates that negative TM expression correlates with advanced stage and tumour grade. On univariate and multivariate analysis tumour differentiation correlated with TM expression, with increasing expression seen in well-differentiated tumours compared with moderate and poorly differentiated $(P<0.001)$ (Figure 4$)$. There was no correlation found between site of tumour and extent of TM tumour staining. A comparison was made between TM tumour cell expression and Jass Score, expression decreasing exponentially as the Jass Score increased (Figure 5). This correlation with Jass score was not identified when comparing TM expression on the vasculature or inflammatory cells.

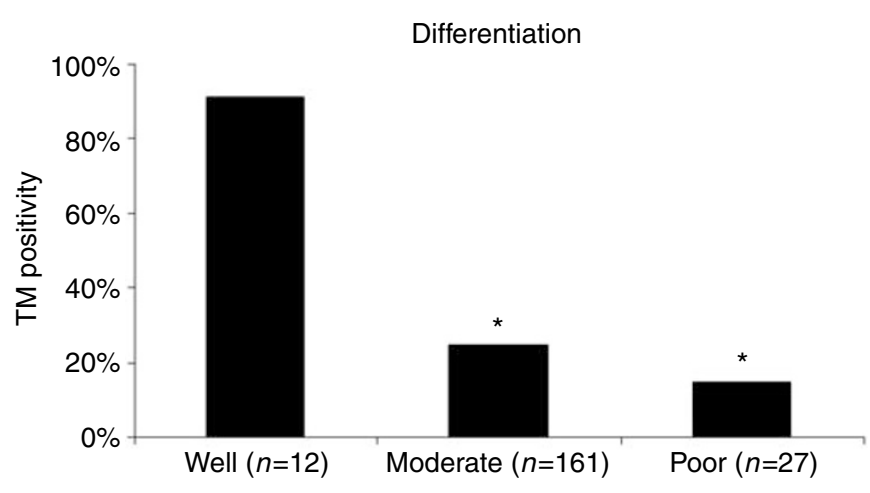

${ }^{*} P<0.001$ compared with well differentiated

Figure 4 This figure demonstrates that over $90 \%$ of well-differentiated tumours were TM positive compared with 24 and I $4 \%$ of moderate and poorly differentiated. Demonstrating increased TM expression in more well-differentiated tumours (Mann-Whitney U-test).

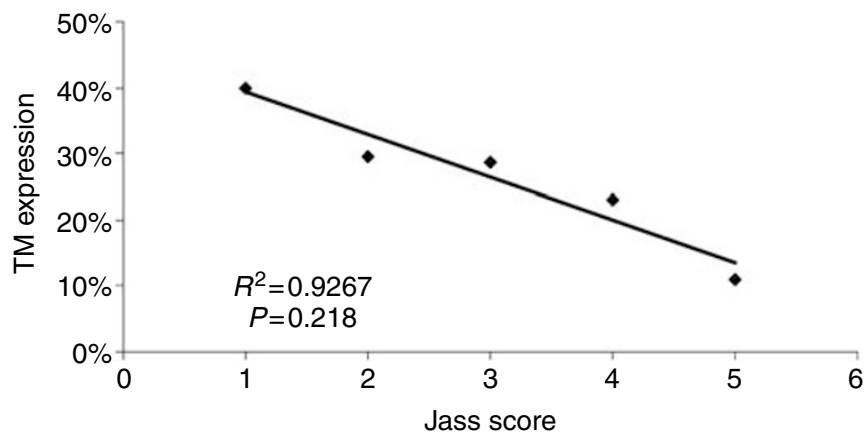

Figure 5 This figure demonstrates that as tumour lass Score increases the amount of TM positive tumours exponentially decreases.

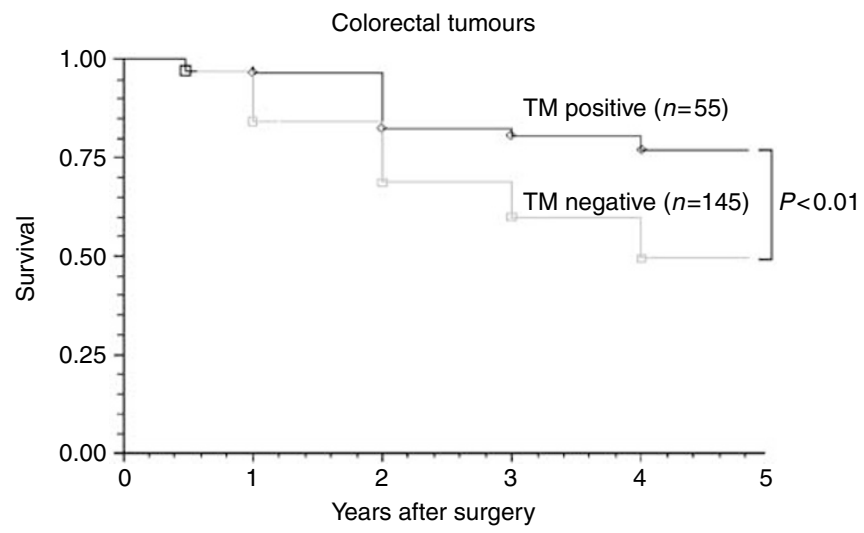

Figure 6 Comparison of the survival between groups which are TM positive and TM negative. The patients who were TM negative showed a significantly poorer survival than those who were TM positive.

A survival analysis was carried out using the Kaplan-Meier method. Clinical data was complete in $100 \%$ of patients. Of the 200 patients included in this study 35 (17.5\%) experienced noncancerrelated deaths and were considered censored in the Kaplan-Meier survival analysis. Comparisons were then made with survival and TM expression groups in the primary tumour. The 5 year survival rates of patients with positive and negative TM expression were 71 and $41 \%$, respectively $(P<0.01)$ (Figure 6 ). 


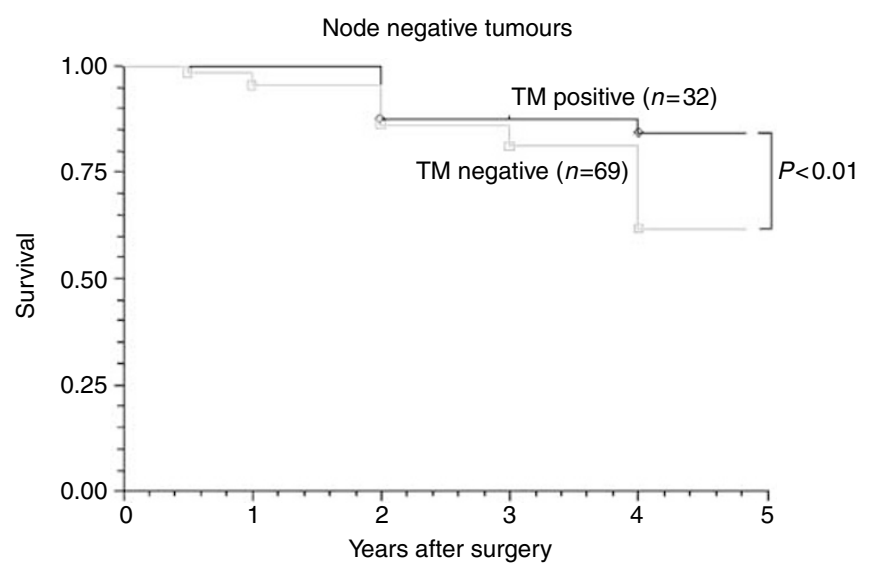

Figure 7 Comparison of the survival between TM positive and TM negative node negative tumours. Patients who are node negative and TM negative show a significantly poorer 5 year survival compared with those who are node negative and TM positive.

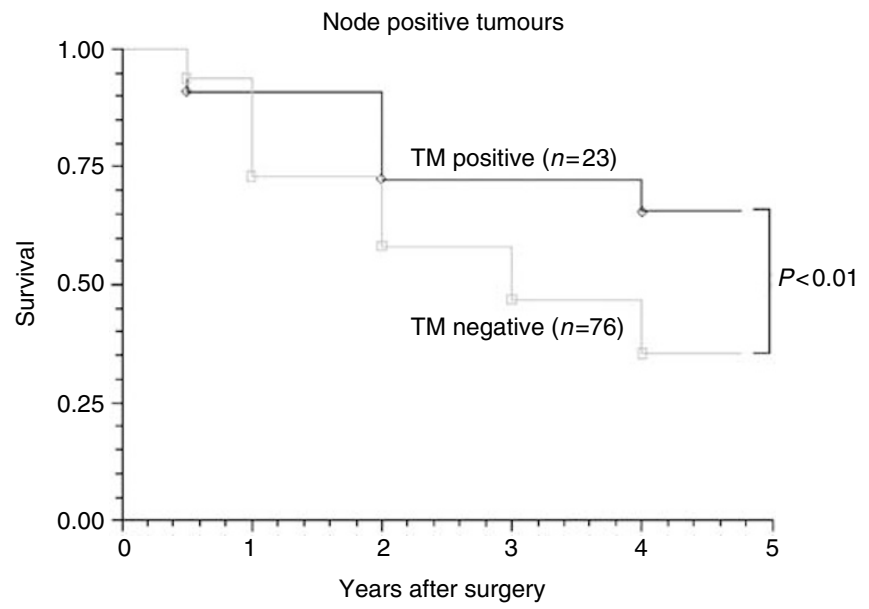

Figure 8 Comparison of the survival between TM positive and TM negative node positive tumours. Patients who are node positive and TM negative show a significantly poorer 5 year survival compared with those who are node positive and TM positive.

We analysed TM expression in the 101 (50.5\%) patients who were node negative. The 5 year survival rates of patients with positive and negative TM expression were 87.5 and $37.8 \%$, respectively $(P<0.01)$ (Figure 7$)$. Comparatively, we analysed those $99(49.1 \%)$ patients, who were node positive, with 23.3 and $76.7 \%$ TM positive and TM negative, respectively. Similar to those who were node negative, 5 year survival was significantly better in those who were TM positive (Figure 8).

All ulcerated tumours expressed membranous TM on inflammatory cells within the ulcer, representing 164 (82\%) of all tumours (Figure 9). TM tumour expression was similar in ulcerated and nonulcerated tumours, with 28 vs 26\% TM positivity in ulcerated and nonulcerated tumours, respectively. Tumour staining was evenly distributed throughout ulcerated tumours and no localization of tumour cell TM expression was noted within or surrounding ulcerated areas. On further analysis patients with ulcerated tumours had poorer 5 year survival rates compared with those without ulceration, 47.1 and $61.1 \%$, respectively $(P<0.01)$. Tumours within the ulcerated group, which expressed TM, demonstrated a similarly improved survival to those in the nonulcerated group. Poorer overall survival in ulcerated tumours could not then be correlated with TM expression.

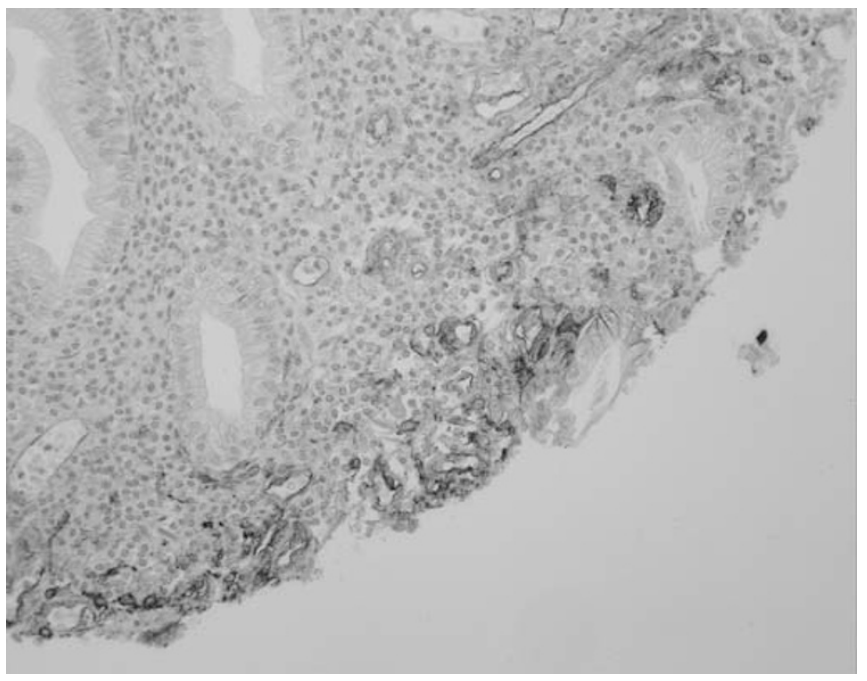

Figure 9 Ulcerated colorectal lesion demonstrating membranous TM staining on the inflammatory cells of the ulcer.

\section{DISCUSSION}

TM is known to be produced predominately by vascular endothelial cells (Esmon, 1989; Lindahl et al, 1993), effecting local as well as systemic action, suggested by its presence in the plasma of healthy individuals (Lindahl et al, 1993). It has been widely investigated as a marker of inflammatory and vascular disease with high plasma and endothelial levels mirroring severity (Weiler and Isermann, 2003). More recently, TM expression was demonstrated constitutively by some epithelial carcinomas, with decreased expression associated with metastases and high recurrence rates (Iino et al, 2004). It was the aim of this study to investigate the expression of TM in a large cohort of primary colorectal adenocarcinomas and to correlate this expression with clinical data.

Tumour cell staining was inversely and significantly correlated with overall stage (Table 2), $\mathrm{T}$ stage (Table 3 ), differentiation (Figure 4), Jass Score (Figure 5) and 5 year survival (Figure 6), suggesting that the presence of TM on colorectal tumour cells inhibits differentiation and may regulate tumour growth and metastasis. TM expression was associated with improved 5 year survival in both node negative and node positive patients. Tumours without TM expression were more likely to be poorly differentiated and have a worse prognosis $(P<0.01)$.

Ulcerated tumours had similar neoplastic cell TM expression compared with nonulcerated tumours. However, ulcerated tumours demonstrated greater TM expression predominantly on inflammatory cells of the ulcer. Ulcerated tumours were associated with poorer survival compared with nonulcerated tumours $(P<0.01)$, despite no significant difference in TM expression, tumour grade or TNM stage. Ulcerated tumours are known to have a worse prognosis compared with nonulcerated tumours, but TM positivity within the ulcerated group was associated with a better prognosis. Poorer survival rates of ulcerated tumours are therefore thought to be independent of TM tumour cell expression.

TM expression on colorectal tumour cells correlated with overall improved survival in this study. In addition, node negative (Dukes' B) and node positive (Dukes' C) tumours independently demonstrated significantly improved survival rates with TM positive $v s$ TM negative expression. It would seem, therefore, that similar to squamous and other epithelial carcinomas, neoplastic TM expression is protective in primary colorectal adenocarcinomas. However, unlike squamous cells where TM is expressed under normal conditions (Mizutani et al, 1996; Yonezawa et al, 1987) only $7.8 \%$ of normal colonic epithelial cells expressed TM. Therefore, while 
colonic epithelial cells do not produce TM under normal conditions, they must be phenotypically capable of doing so in certain environments.

Future work on the manipulation of TM and understanding further its role in proliferation, differentiation and adhesion, will be important in clarifying the function of TM in tumour growth and metastases. There are already many known inducers of TM expression (Hanly et al, 2005) and by understanding the role of
TM in adenocarcinomas, these inducers may provide future potential therapies to modulate tumour behaviour and decrease metastases.

\section{ACKNOWLEDGEMENTS}

We thank Mr Colm Buckley.

\section{REFERENCES}

Calnek DS, Grinnell BW (1998) Thrombomodulin-dependent anticoagulant activity is regulated by vascular endothelial growth factor. Exp Cell Res 238: $294-298$

Conway EM, Van de Wouwer M, Pollefeyt S, Jurk K, Van Aken H, De Vriese A, Weitz JI, Weiler H, Hellings PW, Schaeffer P, Herbert JM, Collen D, Theilmeier G (2002) The lectin-like domain of thrombomodulin confers protection from neutrophil-mediated tissue damage by suppressing adhesion molecule expression via nuclear factor kappaB and mitogenactivated protein kinase pathways. J Exp Med 196: 565-577

de Munk GA, Groeneveld E, Rijken DC (1991) Acceleration of the thrombin inactivation of single chain urokinase-type plasminogen activator (pro-urokinase) by thrombomodulin. J Clin Invest 88: 1680-1684

Dittman WA, Kumada T, Majerus PW (1989) Transcription of thrombomodulin mRNA in mouse hemangioma cells is increased by cycloheximide and thrombin. Proc Natl Acad Sci USA 86: 7179-7182

Esmon CT (1989) The roles of protein C and thrombomodulin in the regulation of blood coagulation. J Biol Chem 264: $4743-4746$

Esmon CT, Owen WG (1981) Identification of an endothelial cell cofactor for thrombin-catalyzed activation of protein C. Proc Natl Acad Sci USA 78: $2249-2252$

Esmon CT, Owen WG (2004) The discovery of thrombomodulin. J Thromb Haemost 2: $209-213$

Grey ST, Csizmadia V, Hancock WW (1998) Differential effect of tumor necrosis factor-alpha on thrombomodulin gene expression by human monocytoid (THP-1) cell $v s$ endothelial cells. Int J Hematol 67: 53-62

Hamatake M, Ishida T, Mitsudomi T, Akazawa K, Sugimachi K (1996) Prognostic value and clinicopathological correlation of thrombomodulin in squamous cell carcinoma of the human lung. Clin Cancer Res 2: $763-766$

Hanly AM, Hayanga A, Winter DC, Bouchier-Hayes DJ (2005) Thrombomodulin: tumour biology and prognostic implications. Eur J Surg Oncol 31: $217-220$

Hosaka Y, Higuchi T, Tsumagari M, Ishii H (2000) Inhibition of invasion and experimental metastasis of murine melanoma cells by human soluble thrombomodulin. Cancer Lett 161: 231-240

Huang HC, Shi GY, Jiang SJ, Shi CS, Wu CM, Yang HY, Wu HL (2003) Thrombomodulin-mediated cell adhesion: involvement of its lectin-like domain. J Biol Chem 278: 46750-46759

Iino S, Abeyama K, Kawahara K, Yamakuchi M, Hashiguchi T, Matsukita S, Yonezawa S, Taniguchi S, Nakata M, Takao S, Aikou T, Maruyama I (2004) The antimetastatic role of thrombomodulin expression in islet cell-derived tumors and its diagnostic value. Clin Cancer Res 10: $6179-6188$

Ikeguchi H, Maruyama S, Morita Y, Fujita Y, Kato T, Natori Y, Akatsu H, Campbell W, Okada N, Okada H, Yuzawa Y, Matsuo S (2002) Effects of human soluble thrombomodulin on experimental glomerulonephritis. Kidney Int 61: $490-501$

Imada S, Yamaguchi H, Nagumo M, Katayanagi S, Iwasaki H, Imada M (1990) Identification of fetomodulin, a surface marker protein of fetal development, as thrombomodulin by gene cloning and functional assays. Dev Biol 140: $113-122$

Iqbal S (2000) Role of thrombomodulin in cancer biology. Breast 9: $264-266$

Ishii H, Tezuka T, Ishikawa H, Takada K, Oida K, Horie S (2003) Oxidized phospholipids in oxidized low-density lipoprotein down-regulate thrombomodulin transcription in vascular endothelial cells through a decrease in the binding of RARbeta-RXRalpha heterodimers and Sp1 and Sp3 to their binding sequences in the TM promoter. Blood 101: 4765-4774

Jackson DE, Mitchell CA, Bird P, Salem HH, Hayman JA (1995) Immunohistochemical localization of thrombomodulin in normal human skin and skin tumours. J Pathol 175: 421-432
Kim SJ, Shiba E, Ishii H, Inoue T, Taguchi T, Tanji Y, Kimoto Y, Izukura M, Takai S (1997) Thrombomodulin is a new biological and prognostic marker for breast cancer: an immunohistochemical study. Anticancer Res 17: $2319-2323$

Lindahl AK, Boffa MC, Abildgaard U (1993) Increased plasma thrombomodulin in cancer patients. Thromb Haemost 69: $112-114$

Maruyama I, Bell CE, Majerus PW (1985) Thrombomodulin is found on endothelium of arteries, veins, capillaries, and lymphatics, and on syncytiotrophoblast of human placenta. J Cell Biol 101: 363-371

Matsushita Y, Yoshiie K, Imamura Y, Ogawa H, Imamura H, Takao S, Yonezawa S, Aikou T, Maruyama I, Sato E (1998) A subcloned human esophageal squamous cell carcinoma cell line with low thrombomodulin expression showed increased invasiveness compared with a high thrombomodulin-expressing clone - thrombomodulin as a possible candidate for an adhesion molecule of squamous cell carcinoma. Cancer Lett 127: 195-201

Mizutani H, Ohyanagi S, Hayashi T, Groves RW, Suzuki K, Shimizu M (1996) Functional thrombomodulin expression on epithelial skin tumours as a differentiation marker for suprabasal keratinocytes. $\mathrm{Br} J$ Dermatol 135: 187-193

Ogawa H, Yonezawa S, Maruyama I, Matsushita Y, Tezuka Y, Toyoyama H, Yanagi M, Matsumoto H, Nishijima H, Shimotakahara T, Aikou T, Sato E (2000) Expression of thrombomodulin in squamous cell carcinoma of the lung: its relationship to lymph node metastasis and prognosis of the patients. Cancer Lett 149: $95-103$

Ohji T, Urano H, Shirahata A, Yamagishi M, Higashi K, Gotoh S, Karasaki Y (1995) Transforming growth factor beta 1 and beta 2 induce downmodulation of thrombomodulin in human umbilical vein endothelial cells. Thromb Haemost 73: 812-818

Ordonez NG (1997) Value of thrombomodulin immunostaining in the diagnosis of transitional cell carcinoma: a comparative study with carcinoembryonic antigen. Histopathology 31: 517-524

Shi J, Wang J, Zheng H, Ling W, Joseph J, Li D, Mehta JL, Ponnappan U, Lin P, Fink LM, Hauer-Jensen M (2003) Statins increase thrombomodulin expression and function in human endothelial cells by a nitric oxidedependent mechanism and counteract tumor necrosis factor alphainduced thrombomodulin downregulation. Blood Coagul Fibrinolysis 14: $575-585$

Tabata M, Sugihara K, Yonezawa S, Yamashita S, Maruyama I (1997) An immunohistochemical study of thrombomodulin in oral squamous cell carcinoma and its association with invasive and metastatic potential. J Oral Pathol Med 26: 258-264

Tabata M, Yonezawa S, Sugihara K, Yamashita S, Maruyama I (1995) The use of thrombomodulin to study epithelial cell differentiation in neoplastic and non-neoplastic oral lesions. J Oral Pathol Med 24: $443-449$

Takebayashi Y, Yamada K, Maruyama I, Fujii R, Akiyama S, Aikou T (1995) The expression of thymidine phosphorylase and thrombomodulin in human colorectal carcinomas. Cancer Lett 92: 1-7

Tezuka Y, Yonezawa S, Maruyama I, Matsushita Y, Shimizu T, Obama $\mathrm{H}_{\text {, }}$ Sagara M, Shirao K, Kusano C, Natsugoe S (1995) Expression of thrombomodulin in esophageal squamous cell carcinoma and its relationship to lymph node metastasis. Cancer Res 55: 4196-4200

Waugh JM, Yuksel E, Li J, Kuo MD, Kattash M, Saxena R, Geske R, Thung SN, Shenaq SM, Woo SL (1999) Local overexpression of thrombomodulin for in vivo prevention of arterial thrombosis in a rabbit model. Circ Res 84: $84-92$

Weiler H, Isermann BH (2003) Thrombomodulin. J Thromb Haemost 1: $1515-1524$

Weiler H, Lindner V, Kerlin B, Isermann BH, Hendrickson SB, Cooley BC, Meh DA, Mosesson MW, Shworak NW, Post MJ, Conway EM, Ulfman 
LH, von Andrian UH, Weitz JI (2001) Characterization of a mouse model for thrombomodulin deficiency. Arterioscler Thromb Vasc Biol 21: $1531-1537$

Wilhelm S, Schmitt M, Parkinson J, Kuhn W, Graeff H, Wilhelm OG (1998) Thrombomodulin, a receptor for the serine protease thrombin, is decreased in primary tumors and metastases but increased in ascitic fluids of patients with advanced ovarian cancer FIGO IIIc. Int J Oncol 13: $645-651$
Yonezawa S, Maruyama I, Sakae K, Igata A, Majerus PW, Sato E (1987) Thrombomodulin as a marker for vascular tumors. Comparative study with factor VIII and Ulex europaeus I lectin. Am J Clin Pathol 88: 405-411

Zhang Y, Weiler-Guettler H, Chen J, Wilhelm O, Deng Y, Qiu F, Nakagawa K, Klevesath M, Wilhelm S, Bohrer H, Nakagawa M, Graeff H, Martin E, Stern DM, Rosenberg RD, Ziegler R, Nawroth PP (1998) Thrombomodulin modulates growth of tumor cells independent of its anticoagulant activity. J Clin Invest 101: $1301-1309$ 